\title{
Phenolic composition of vine leaves infusions produced from different Portuguese and Spanish Vitis vinifera L. varieties
}

\author{
A.M. Jordão ${ }^{1,2, a}$, J. Sousa ${ }^{2}$, A.C. Correia ${ }^{1}$, M.E. Valdés ${ }^{3}$, F.M. Nunes ${ }^{4}$, and F. Cosme ${ }^{5}$ \\ ${ }^{1}$ Instituto Politécnico de Viseu (CI\&DETS), 3500-606 Viseu, Portugal \\ ${ }^{2}$ Centro de Química de Vila Real (CQ-VR), Laboratório de Química Alimentar e do Vinho, 5001-801 Vila Real, Portugal \\ ${ }^{3}$ Centro de Investigaciones Científicas y Tecnológicas de Extremadura, Instituto Tecnológico Agroalimentario de Extremadura, \\ Badajoz, España \\ ${ }^{4}$ Centro de Química de Vila Real (CQ-VR), Laboratório de Química Alimentar e do Vinho, Universidade de Trás-os-Montes e Alto \\ Douro, Departamento de Química, 5001-801 Vila Real, Portugal \\ ${ }^{5}$ Centro de Química de Vila Real (CQ-VR), Laboratório de Química Alimentar e do Vinho, Universidade de Trás-os-Montes e Alto \\ Douro, Departamento de Biologia e Ambiente, 5001-801 Vila Real, Portugal
}

\begin{abstract}
The main object of the present study was to analyze the phenolic composition of vine leaves infusions prepared from 8 different Portuguese (Fernão Pires, Touriga Franca, Tinta Roriz, Encruzado, Touriga Nacional, Rufete, Baga, and Siria) and Spanish (Pardina, Cayetana, Garnacha, Cigüente, Eva, Tempranillo, Macabeo and Verdelho) Vitis vinifera L. varieties. In general, a wide range of phenolic content were obtained from the vine leaves infusions according to the vine variety used. Thus, for total phenolic content the values ranged from 18 to $37 \mathrm{mg} / \mathrm{L}$ for the infusions produced from Portuguese varieties, while for Spanish varieties the values ranged from 14 to $37 \mathrm{mg} / \mathrm{L}$. Vine leaves infusions obtained from Touriga Franca and Pardina varieties showed the highest total phenolic content. As a consequence of phenolic composition, chromatic characteristics ( $L^{*}, a^{*}$ and $b^{*}$ ) of vine leaves infusions were also analyzed. Finally, it was also detected different individual phenolic compounds, such as, coutaric acid, trans-caftaric acid, quercetin-3$O$-glucoside, rutin and 3 different anthocyanins from the different vine leaves infusions. All of the results obtained in this work show that vine leaves infusion may be an interesting alternative source of phenolic compounds for human diet.
\end{abstract}

\section{Introduction}

Phenolic compounds are secondary metabolites widely found in the different parts of the plants mainly in their fruits. This important group of compounds, mostly represented by flavonoids and non flavonoids, contributes to some beverage sensory characteristics such as color, astringency and bitterness [1,2]. In addition, these compounds have gained considerable interest due to the association between their consummation and the health benefits, especially as natural antioxidants [3]. The health benefits of these phytochemicals are directly linked to a regular intake and their bioavailability. In this context, the products obtained from the vine, in particular grapes, have been deeply studied as important sources of phenolic compounds $[4,5]$. However, from vines, other plant parts could be harnessed, namely vine leaves. In that case, vine leaves may be potentially interesting for the production of herbal infusions. This is a potential alternative not fully exploited for vine leaves valorization after grape harvest. In addition, it is important to note that, the consumption of teas and herbal infusions has increased in Europe and the USA in recent years [6]. Therefore, the potential use of vine leaf infusions may be an interesting option for the habitual infusion consumers, opening up the range of options for this type of products

a e-mail: antoniojordao@esav.ipv.pt and at same time increasing the economical valorization of vines. Furthermore, vine leaves infusion may be a potential alternative source of bioactive compounds (such as, phenolic compounds) for human diet, besides being caffeine-free infusions which may be a further advantage because some consumers have some sensitivity to this compound present in the teas.

Thus, the main purpose of the present study was to investigate the phenolic composition of vine leaves infusions prepared from 8 different Portuguese and Spanish Vitis vinifera L. varieties.

\section{Material and methods}

\subsection{Material and infusions preparation}

Vine leaves infusions were prepared from different Portuguese (Fernão Pires, Touriga Franca, Tinta Roriz, Encruzado, Touriga Nacional, Rufete, Baga, and Siria) and Spanish (Pardina, Cayetana, Garnacha, Cigüente - syn. Doña Blanca, Eva, Tempranillo, Macabeo and Verdelho) Vitis vinifera $\mathrm{L}$. varieties. All vine leaves were sampled between 30 and 40 days after grape harvest. Afterward, all vine leaves were dried at room temperature $\left( \pm 22^{\circ} \mathrm{C}\right)$ under totally dark conditions until a final humidity of 6-8\%. Then, dried vine leaves were crushed (final particle size 
(a)

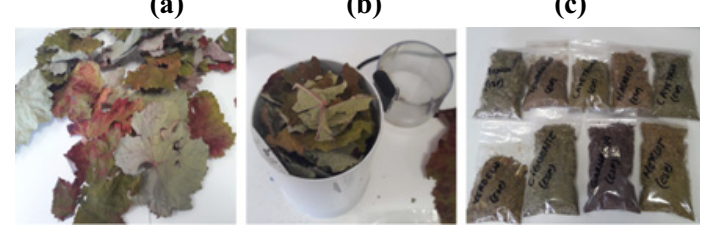

Figure 1. Visual appearance of dried vine leaves (a), crush process (b) and stored vine leaves in sachets (c).

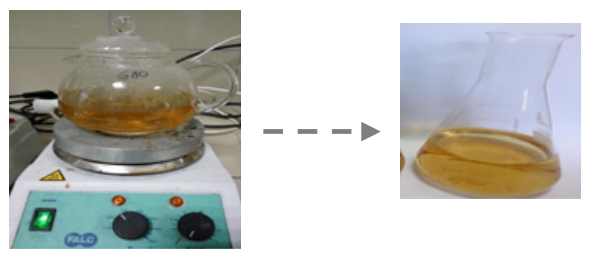

Figure 2. Vine leaves infusions preparation.

of $2-8 \mathrm{~mm}$ ) and stored in sachets until used for infusions production (Fig. 1).

For the production of vine leaves infusions (in duplicate), leaves samples from the different varieties were placed in boiling water at a concentration of $1.5 \mathrm{~g} / \mathrm{L}$ during 10 minutes. After this time, vine leaves infusions were filtered prior to the phenolic analysis (Fig. 2).

\subsection{Methodologies}

Several phenolic parameters were used for vine leaves phenolic characterization: total phenols [7], flavonoid and non flavonoid phenolic compounds [8], and total anthocyanins [9]. Individual phenolic compounds were analysis by HPLC-DAD following the methodology described previously by Guise et al. [10]. Finally, using the CIELab method (scanned from a range of 380-770 nm), chromatic characteristics were also calculated: $L^{*}$ (lightness), $a^{*}$ (redness) and $b^{*}$ (yellowness), according to the OIV method [11]. All laboratory measurements were performed in triplicate.

\subsection{Statistical analysis}

The data are presented as mean \pm standard deviation. To determine whether there is a statistically significant difference between the data obtained for the diverse parameters quantified in the vine leaves infusions samples, an analysis of variance (ANOVA, one-way) and comparison of treatment means were carried out using the Tukey test $(p<0.05)$. This analysis was performed using Statistica software (version 10.0).

\section{Results and discussion}

Figure 3 shows the results obtained for divers phenolic parameters (total phenols, flavonoid and non flavonoid phenols and total anthocyanins) quantified in the different vine leaves infusions produced from several Vitis vinifera varieties. By the analysis of Fig. 3, it is clear that it was possible to detect a high variation of the values for the different phenolic parameters studied.

Data points derived for each phenolic parameter showing the same letter are not significantly different $(p<0.05)$.
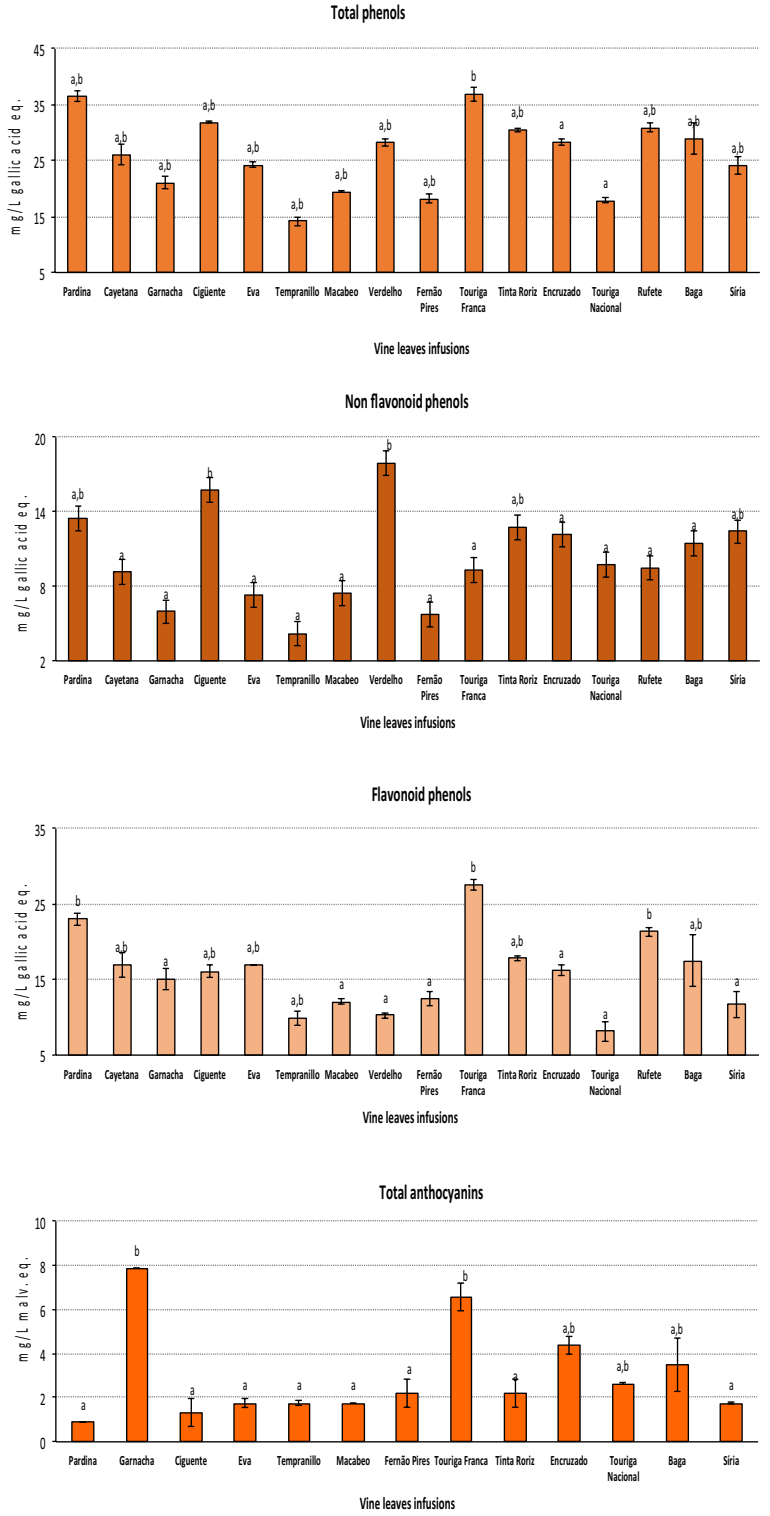

Figure 3. Several phenolic parameters quantified in the different vine leaves infusions produced from diverse Vitis vinifera L. varieties.

It is obvious a high range of the total phenolic content quantified in the different vine leaves infusions independently of the vine variety (values ranged from 14 to $37 \mathrm{mg} / \mathrm{L}$ gallic acid equivalents). In addition, the use of red or white vine varieties didn't induced a clear differentiation of total phenolic content quantified in the vine leaves infusions. This was clear in the infusions obtained from Verdelho and Pardina varieties (28 and $36 \mathrm{mg} / \mathrm{L}$ gallic acid equivalents, respectively) which are white varieties as opposed to the values obtained for infusions derived from some red varieties, such as, Tempranillo and Touriga Nacional varieties (15 and $18 \mathrm{mg} / \mathrm{L}$ gallic acid equivalents, respectively). Fernandes et al. [12] reported significant differences in the volatile composition of the leaves from two red grape varieties (Touriga Nacional and Tinta Roriz), but these differences were not reflected in the composition of the vine leaf infusion made from these two varieties. Thus, there were several factors during the infusions production (such as, maceration time, temperature used, among others) that could influence the final composition of the vine leaf infusions. 
Regarding to non flavonoid phenolic compounds (Fig. 3), the infusions produced from Verdelho and Cigüente varieties, showed the significantly highest values (18 and $16 \mathrm{mg} / \mathrm{L}$ gallic acid equivalents, respectively), while the infusion obtained from Tempranillo cultivar showed the lowest value ( $4 \mathrm{mg} / \mathrm{L}$ gallic acid equivalents). It is important to point out that infusions with higher non flavonoid phenolic contents were obtained from 2 important white varieties, the Cigüente variety being a Spanish variety cultivated in several regions of Spain and Verdelho that is a variety that can be found in several regions of Spain and Portugal. Non-flavonoid phenolic compounds include the stilbenoids such as resveratrol and phenolic acids such as benzoic, caffeic and cinnamic acids. Some of these individual phenolic compounds, such as resveratrol are important bioactive compounds with a potential health benefits [13].

Flavonoid phenols cover a large number of subclasses, such as flavonols, flavanols, and anthocyanins. Thus, for this phenolic group, infusions from Touriga Franca and Pardina varieties showed the highest flavonoid content (28 and $23 \mathrm{mg} / \mathrm{L}$ gallic acid equivalents, respectively) while the lowest values were quantified in vine leaves infusions from Touriga Nacional cultivar $(8 \mathrm{mg} / \mathrm{L}$ gallic acid equivalents). According to Katalinic et al. [14] the phenolic potential of vine leaves extracts are dependent on variety and picking-time. For these authors, vine leaves collected in September were the richest in total phenols, flavonoids, flavonols and stilbenes.

For all vine leave infusions low levels of total anthocyanins were detected (Fig. 3), where the two infusions obtained from red varieties showed the significantly highest values (Garnacha and Touriga Franca, 7.87 and $6.56 \mathrm{mg} / \mathrm{L}$ malvindin- $O$-monoglucoside equivalents, respectively). One of the causes for the very low values of anthocyanin content may be due not only to the natural low levels of anthocyanins present in the leaves, but also due to the degradation of these compounds during the vine leaves drying and additionally due to the high temperatures used in the infusions preparation, in particular during the maceration process. Also for infusions produced from white grape varieties a slight anthocyanin content was detected (for example for the infusions obtained from Cayetana, Verdelho, Siria, Cigüente and Fernão Pires). It is important to note that also for white grape varieties several authors reported previously low levels of anthocyanins in the grape berry $[15,16]$.

The results obtained for the vine leave infusions CIELab paramters are shown in Table 1. For lightness $\left(L^{*}\right)$, among the vine leave infusions, in general all $L^{*}$ values were similar. However, vine infusions produced from Verdelho and Encruzado (two white grape varieties) showed the significantly lowest $L^{*}$ values. Concerning to $a^{*}$ values (redness) all values obtained for the vine leaves infusions were very low and some of them negatives (a tendency for green color). The low red color confirm the slight levels of anthocyanin content quantified in all infusions (Fig. 3) and consequently these results follow the same trend to that obtained for the total anthocyanin values quantified for the different vine leave infusions. Finally for $b^{*}$ (yellowness) values, infusions produced from white grape varieties (Verdelho, Encruzado, Pardina, Eva and Cigüente) showed in general the significantly
Table 1. Vine leaves infusions chromatic characteristics using the CIELAB method.

\begin{tabular}{lccc}
\hline Vine leaves & \multicolumn{3}{c}{ Chromatic coordinates } \\
\cline { 2 - 4 } infusions & $\mathbf{L}^{*}$ & $\mathbf{a}^{*}$ & $\mathbf{b}^{*}$ \\
\hline Pardina & $92.93 \pm 0.02^{\mathrm{b}}$ & $0.97 \pm 0.01^{\mathrm{e}}$ & $19.17 \pm 0.11^{\mathrm{i}}$ \\
Cayetana & $96.44 \pm 0.08^{\mathrm{cd}}$ & $-0.07 \pm 0.02^{\mathrm{c}}$ & $10.94 \pm 0.03^{\mathrm{f}}$ \\
Garnacha & $96.02 \pm 0.04^{\mathrm{cd}}$ & $0.44 \pm 0.03^{\mathrm{d}}$ & $7.83 \pm 0.09^{\mathrm{cd}}$ \\
Cigüente & $92.13 \pm 1.80^{\mathrm{b}}$ & $0.11 \pm 0.36^{\mathrm{cd}}$ & $15.42 \pm 0.41^{\mathrm{g}}$ \\
Eva & $94.12 \pm 0.02^{\mathrm{b}}$ & $1.86 \pm 0.03^{\mathrm{f}}$ & $16.23 \pm 0.15^{\mathrm{h}}$ \\
Tempranillo & $98.10 \pm 0.19^{\mathrm{d}}$ & $-0.56 \pm 0.08^{\mathrm{b}}$ & $4.94 \pm 0.07^{\mathrm{a}}$ \\
Macabeo & $95.55 \pm 0.40^{\mathrm{c}}$ & $-0.01 \pm 0.10^{\mathrm{cd}}$ & $9.33 \pm 0.03^{\mathrm{e}}$ \\
Verdelho & $88.94 \pm 0.81^{\mathrm{a}}$ & $1.18 \pm 0.28^{\mathrm{e}}$ & $21.02 \pm 0.28^{\mathrm{f}}$ \\
Fernão Pires & $96.59 \pm 0.09^{\mathrm{cd}}$ & $-0.46 \pm 0.04^{\mathrm{b}}$ & $6.59 \pm 0.03^{\mathrm{b}}$ \\
Touriga Franca & $95.38 \pm 0.01^{\mathrm{c}}$ & $1.25 \pm 0.03^{\mathrm{e}}$ & $11.50 \pm 0.12^{\mathrm{f}}$ \\
Tinta Roriz & $94.19 \pm 0.02^{\mathrm{b}}$ & $-0.60 \pm 0.01^{\mathrm{b}}$ & $11.55 \pm 0.21^{\mathrm{f}}$ \\
Encruzado & $90.09 \pm 0.41^{\mathrm{a}}$ & $1.39 \pm 0.06^{\mathrm{ef}}$ & $21.32 \pm 0.03^{\mathrm{j}}$ \\
Touriga & $97.42 \pm 0.07^{\mathrm{cd}}$ & $-0.83 \pm 0.04^{\mathrm{b}}$ & $6.95 \pm 0.14^{\mathrm{b}}$ \\
Nacional & & & \\
Rufete & & & \\
Baga & $97.00 \pm 0.06^{\mathrm{cd}}$ & $-1.39 \pm 0.01^{\mathrm{a}}$ & $7.62 \pm 0.02^{\mathrm{c}}$ \\
Síria & $96.13 \pm 0.14^{\mathrm{cd}}$ & $0.04 \pm 0.01^{\mathrm{cd}}$ & $8.31 \pm 0.08^{\mathrm{d}}$ \\
\hline$L^{*}$ (lightness); $a^{*}$ (redness); $b^{*}(\mathrm{yellowness)} \mathrm{Data} \mathrm{points} \mathrm{derived} \mathrm{for} \mathrm{each}$ \\
chromatic coordinate showing the same letter are not significantly different \\
( $p<0.05$ ). & & &
\end{tabular}
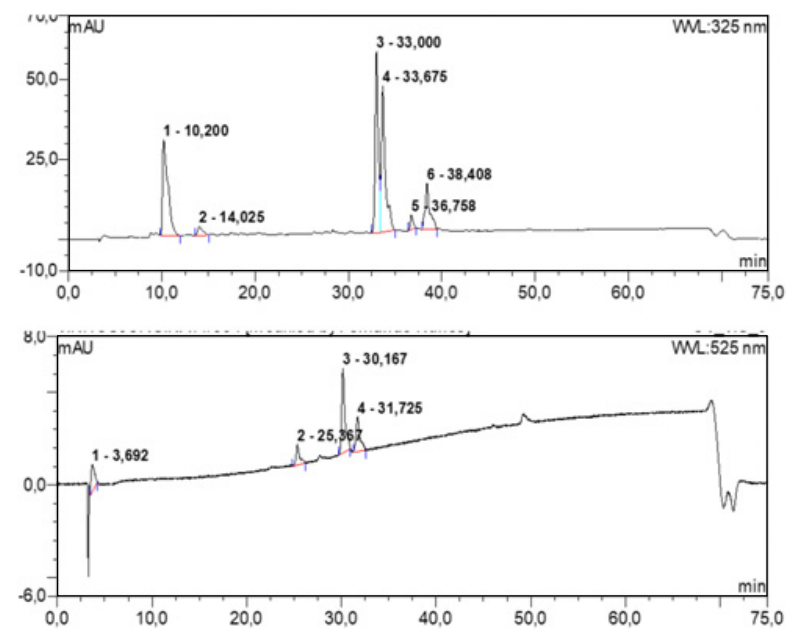

Figure 4. HPLC chromatographic profiles found in vine leaves infusions at 325 and $525 \mathrm{~nm}$. Legend peaks: at $325 \mathrm{~nm}$ (1) transcaftaric acid; (2) coutaric acid; (3) quercetin-3-O-glucoside; (4) rutin; (6) unknow flavonol; at $525 \mathrm{~nm}$ (2) petunidin-3- $O$ monoglucoside; (3) peonidin-3- $O$-monoglucoside; (4) malvidin3-O-monoglucoside.

highest values. All these chromatic characteristics will be important for the sensory perception of the different vine leave infusions.

Figure 4 shows two HPLC chromatographic profiles found in vine leaves infusions obtained at 325 and $525 \mathrm{~nm}$. Thus, 8 individual phenolic compounds were detected. At $325 \mathrm{~nm}$, trans-cafftaric acid, coutaric acid, quercetin-3-O-glucoside, rutin and also an unknown flavonol were detected, while at $525 \mathrm{~nm}, 3$ different individual anthocyanins were identified (petunidin3- $O$-monoglucoside, peonidin-3- $O$-monoglucoside and malvidin-3- $O$-monoglucoside).

Figure 5 shows the trans-caftaric, quercetin-3-Oglucoside and rutin content quantified in the different vine leaves infusions studied. In all vine leaves infusions 


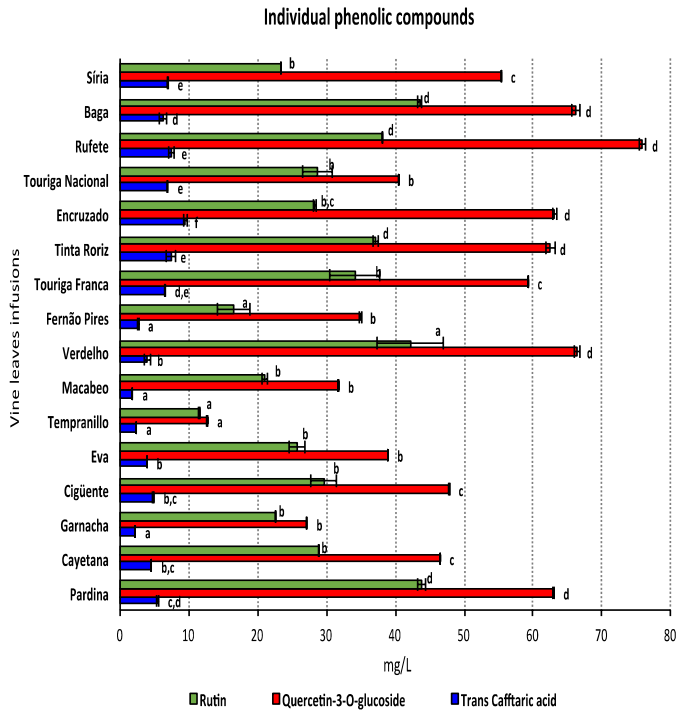

Figure 5. Three different phenolic compounds quantified in the vine leaves infusions produced from diverse Vitis vinifera $\mathrm{L}$. varieties.

Data points derived for each individual phenolic compound showing the same letter are not significantly different $(p<0.05)$.

was possible to quantify one phenolic acid, one flavonol and one flavonoid. Its was clear that quercetin-3-Oglucoside was the most abundant flavonol quantified in vine leaves infusions (values varied from 12.70 to $75.92 \mathrm{mg} / \mathrm{L}$, respectively for Tempranillo and Rufete varieties), following by rutin (values varied from 11.53 to $43.77 \mathrm{mg} / \mathrm{L}$, respectively for Tempranillo to Pardina varieties) and trans-caftaric acid (values varied from 1.83 to $9.46 \mathrm{mg} / \mathrm{L}$, respectively for Macabeo and Encruzado varieties).

Coutaric acid was the phenolic acid quantified in lowest values in all vine leave infusions, varied from 0.31 to $0.93 \mathrm{mg} / \mathrm{L}$, respectively for Macabeo and Rufete varieties (data not show).

For a varietal point of view, vine leaves infusions produced from Tempranillo variety showed the lowest values of the three individual phenolic compounds quantified (Fig. 5), while vine leaves infusions made from Rufete, Verdelho, Pardina and Baga varieties showed significantly highest values for three individual phenolic compounds quantified. In addition, it was not clear a differentiation between the infusions produced from red and white vine varieties.

Finally, only a few individual monoglucoside anthocyanins (petunidin-3- $O$-monoglucoside, peonidin-3- $O$ monoglucoside and malvidin-3- $O$-monoglucoside) were detected in the several vine leaves infusions studied (Table 2). Thus, only for the infusions produced from Garnacha, Touriga Franca, Tempranillo, Baga and Síria varieties was possible to quantified some individual monoglucoside anthocyanins. Again, it was possible to detected individual monoglucoside anthocyanins in vine leaves infusions produced from Siria variety, which is a white vine variety, confirming the results obtained for total anthocyanins (Fig. 3), and also the data published previously by other authors in grapes and wines from this variety [15]. Finally, the results obtained followed the same trend detected for total anthocyanins, that is, infusions obtained from Garnacha and Touriga Franca
Table 2. Individual monoglucoside anthocyanins quantified in 5 different vine leaves infusions produced from various Vitis vinifera $\mathrm{L}$. varieties.

\begin{tabular}{lccc}
\hline Vine leaves & \multicolumn{3}{c}{ Individual anthocyanins } \\
\cline { 2 - 4 } infusions & Pet. & Peo. & Malv. \\
\hline Garnacha & $0.18 \pm 0.07^{\mathrm{a}}$ & $0.62 \pm 0.06^{\mathrm{c}}$ & $0.49 \pm 0.01^{\mathrm{c}}$ \\
Touriga Franca & $0.67 \pm 0.02^{\mathrm{c}}$ & $0.59 \pm 0.01^{\mathrm{c}}$ & n.d. \\
Tempranillo & n.d. & n.d. & $0.17 \pm 0.01^{\mathrm{b}}$ \\
Baga & $0.26 \pm 0.01^{\mathrm{b}}$ & $0.27 \pm 0.02^{\mathrm{b}}$ & $0.01 \pm 0.00^{\mathrm{b}}$ \\
Síria & $0.25 \pm 0.01^{\mathrm{b}}$ & $0.07 \pm 0.00^{\mathrm{a}}$ & n.d. \\
\hline
\end{tabular}

n.d. - not detected; Pet. - petunidin-3- $O$-monoglucoside; Peo. - peonidin3-O-monoglucoside; malv. - malvidin-3- $O$-monoglucoside; Data points derived for each individual anthocyanin showing the same letter are not significantly different $(p<0.05)$.

varieties showed the significantly highest values. The high temperatures used for infusions production could be a key factor for the low content o individual anthocyanins detected.

\section{Final remarks}

The results obtained in this work could be important to contribute for the selection the vine leaves with higher phenolic content for infusions production. However, further research, including other detailed analysis, such as, antioxidant capacity, amino acid content and nutritional value, will be important to establish the vine leaves varieties with more potential for infusions production. In addition, the sensory profile of vine leaves produced from different vine varieties will also another important point for consumer acceptance.

All of these topics will be critical points to improve the knowledge about the quality of vine leaves infusions and particularly the potential health benefits and at same time, to improve the economical valorization of vine leaves collected after grape harvest.

Authors thanks to FCT (projects UID/Multi/04016/2016 and PEst-OE/QUI/UI0616/2014), Chemistry Research Centre in Vila Real (CQ-VR) and IPV-CI\&DETS for their financial support.

\section{References}

[1] M.P. Saenz-Navajas, V. Ferreira, M. Dizy, P. Fernandez-Zurbano, Anal. Chim. Acta. 673 151 (2010)

[2] G.R. Beecher, J. Nutr. 133, 3248 (2003)

[3] R.J. Gryglewski, R. Korbut, J. Robak, J. Swies, Biochem Pharmacol. 36, 317 (1987)

[4] A.M. Jordão, J.M. Ricardo-da-Silva, O. Laureano, Vitis 40, 17 (2001)

[5] E. Costa, F. Cosme, A.M. Jordão, A. Mendes-Faia, J. Int. Sci. Vigne Vin 48, 51 (2014)

[6] A.A. Izzo, S. Hoon-Kim, R. Radhakrishnan, E.M. Williamson, Phytother. Res. 30, 691 (2016)

[7] P. Ribéreau-Gayon, Y. Glories, A. Maujean, D. Dubourdieu, In Handbook of Enology: The Chemistry of Wine Stabilization and Treatments, vol. 2 (Wiley \& Sons Ltd, editors, 2006)

[8] T.E. Kramling, V.L. Singleton, Am. J. Enol. Vitic. 20, 86 (1969)

[9] P. Ribéreau-Gayon, E. Stronestreet, Bull Soc. Chim. 9, 2649 (1965) 
[10] R. Guise, L. Filipe-Ribeiro, D. Nascimento, O. Bessa, F.M. Nunes, F. Cosme, Food Chem. 156, 250 (2014)

[11] OIV, International Oenological Codex (Edition Officielle, Paris, 2012)

[12] B. Fernandes, A.C. Correia, F. Cosme, F.M. Nunes, A.M. Jordão, Nat. Prod. Res. 29, 37 (2015)

[13] E. Frankel, J. Kanner, J.B. German, E. Parks, J.E. Kinsella, Lancet 341, 454 (1993)
[14] V. Katalinic, S.S. Mozina, I. Generalic, D. Skroza, I. Ljubenkov, A. Klancnik, Int. J. Food Prop. 16, 45 (2013)

[15] J. Andrea-Silva, F. Cosme, L. Filipe Ribeiro, A.S.P. Moreira, A.C. Malheiro, M.A. Coimbra, M.R.M. Domingues, F.M. Nunes, J. Agric. Food Chem. 62, 5651 (2014)

[16] P. Arapitsas, J. Oliveira, F. Mattivi, Food Res Int. 69, $21(2015)$ 